\title{
Comparing methods for the assessment of reproductive activity in adult male loggerhead sea turtles Caretta caretta at Cape Canaveral, Florida
}

\author{
Gaëlle Blanvillain $^{1, *}$, Anthony P. Pease ${ }^{2}$, Al L. Segars ${ }^{3}$, David C. Rostal ${ }^{4}$, \\ Adam J. Richards ${ }^{5}$, David W. Owens ${ }^{1}$ \\ ${ }^{1}$ College of Charleston, Grice Marine Laboratory, 205 Ft. Johnson Rd, Charleston, South Carolina 29412, USA \\ ${ }^{2}$ North Carolina State University, 4700 Hillsborough Street, Raleigh, North Carolina 27606, USA \\ ${ }^{3}$ South Carolina Department of Natural Resources (SCDNR), 32 Fiddler Drive, Beaufort, South Carolina 29902, USA \\ ${ }^{4}$ Georgia Southern University, PO Box 8042, Statesboro, Georgia 30460, USA \\ ${ }^{5}$ Medical University of South Carolina, Department of Bioinformatics and Epidemiology, 135 Cannon Street, Suite 303, \\ Charleston, South Carolina 29425, USA
}

\begin{abstract}
In an attempt to better understand the reproductive cycle of adult male loggerhead sea turtles, several techniques were used to assess their reproductive activity, including plastron-softness analysis, ultrasonography, laparoscopy, testicular biopsy samples, and measuring testosterone levels. Stress levels were evaluated on a subset of turtles by measuring testosterone and corticosterone concentrations after capture and before release. A total of 40 adult males were captured in the Port Canaveral shipping channel in April of 2006 and 2007. Four turtles were classified as reproductively inactive based on laparoscopic examination, histology of the testes, and testosterone levels. The relative area of plastron softness was significantly lower for the inactive males compared to the active males. Ultrasonography proved to be a promising tool, as we were able to visualize both the testes and epididymides on the turtles examined. Furthermore, we found no statistical difference in epididymal duct diameters measured by ultrasonography and during laparoscopy, suggesting that ultrasonography could be used successfully as a substitute for laparoscopic surgery. Finally, testosterone levels separated into 2 distinct groups, with concentrations of the inactive males below $5 \mathrm{ng} \mathrm{ml}^{-1}$, and concentrations of the active males reaching $188 \mathrm{ng} \mathrm{ml}^{-1}$. We conclude that in order to reduce stress levels due to capture and handling, especially during laparoscopy, ultrasonography and plastron analysis could be used together as a way to determine the reproductive activity of adult males in the field. The results from this study also suggest that not all adult males participate in mating activity each year.
\end{abstract}

KEY WORDS: Reptilia · Caretta caretta - Laparoscopy · Ultrasound · Histology · Plastron softness · Testosterone $\cdot$ Corticosterone

Resale or republication not permitted without written consent of the publisher

\section{INTRODUCTION}

Adult male sea turtles spend their entire lives in the oceanic environment, which makes them logistically and financially difficult to study. As a result, the vast majority of what we know about adult sea turtles has been learned from the short period of time when females come back on land to nest. Hence, there is a large gap in our knowledge of adult male biology and life history compared to that of adult females, eggs, and hatchlings. For example, little is known of male migratory routes or reproductive biology, and much work needs to be done in these areas to better understand and ultimately protect these threatened or endangered marine species.

Adult male sea turtles are thought to undertake breeding migrations, given their increased abundance adjacent to nesting beaches prior to the onset of nest- 
ing. Such behavior has been observed for loggerheads Caretta caretta in the southeastern USA (Henwood 1987, Frick et al. 2000) and also green turtles Chelonia mydas in the southern Great Barrier Reef (Limpus 1993). Genetic data suggest that male Australian greens exhibit a degree of natal homing (FitzSimmons et al. 1997); however, it is unknown whether male loggerheads exhibit similar behavior.

The reproductive biology of adult male loggerhead sea turtles is not well known and deserves further attention. For example, it is not known whether males mate every year, or if they undergo multi-annual remigration cycles as females do. Several studies have shown that some male green sea turtles were non-breeding during a given season, possibly due to environmental constraints such as food quality and availability (Limpus 1993, Jessop et al. 2004). The evaluation of the reproductive activity in adult males has mainly been studied by laparoscopy, which allows direct visualization of the gonads, involves surgery and anesthesia, and can be performed by trained scientists or veterinarians. The knowledge of reproductive activity level of adult male sea turtles is of importance not only for a basic understanding of their biology, but also in satellite telemetry studies aimed at discovering migratory paths taken by reproductively active males to and from their mating areas. Given the cost of such studies, a validation of the reproductive status of those males would be needed before deploying satellite tags. Conversely, no satellite telemetry studies have involved known reproductively inactive adult males. Such data could shed light on remigration intervals and behavior during this interval. Finally, with global warming potentially feminizing sea turtle populations worldwide, males might become the limiting resource; thus better knowledge of their mating cycles and remigration intervals will become extremely important in understanding the impact of this global phenomenon on these threatened species.

The goal of this study was to collect adult male loggerheads in the Port Canaveral shipping channel, Florida, and to compare several techniques that vary in degree of invasiveness to assess male loggerhead reproductive activity. The techniques evaluated included plastronsoftness analysis, ultrasonography, laparoscopy, histology of the testes, and measuring testosterone levels. In addition, during the second year of the study, we estimated the level of stress these males were experiencing by measuring testosterone and corticosterone levels directly after capture and just before release.

\section{MATERIALS AND METHODS}

Capture and handling of turtles. Sea turtles were collected by trawling aboard the RV 'Georgia Bulldog', a $22 \mathrm{~m}$ research trawler equipped with paired $18.3 \mathrm{~m}$ wide flat nets. Trawling was conducted in the Port Canaveral shipping channel, between buoys 1 and 9 . Tow time was set to $15 \mathrm{~min}$. Trawling was conducted $5 \mathrm{~d}$ in 2006 (April 17 to 21) and $10 \mathrm{~d}$ in 2007 (April 2 to 6 and April 25 to 28). We captured a total of 11 adult males in 2006, 12 during the first week of trawling in 2007, and 17 during the second week of trawling in 2007 (including 2 recaptures: 1 from 2006, 1 from the first week in 2007), for which we have collected information using a minimum of 2 methods of reproductive assessment.

Sampling. For all 40 turtles, we collected approximately $8 \mathrm{ml}$ of blood from the dorsocervical sinus (Owens \& Ruiz 1980) using sterile, $10 \mathrm{ml}$ vacutainer tubes (with sodium heparin) fitted with $3.81 \mathrm{~cm}, 20$ gauge double-ended needles (Becton-Dickinson). To reduce measurement variability due to capture and handling stress, blood samples were taken within about $15 \mathrm{~min}$ after the turtles were removed from the nets. In 2007, we collected a second blood sample just before release (except for 2 turtles released almost immediately after capture) and recorded the time between the 2 samples. We stored samples on ice, centrifuged them for $5 \mathrm{~min}$, and pipetted about $5 \mathrm{ml}$ of plasma into cryogenic vials before placing them in liquid nitrogen. In the laboratory, samples were stored at $-80^{\circ} \mathrm{C}$ until further analysis. For each turtle, we recorded a set of measurements to the nearest $0.1 \mathrm{~cm}$ using measuring tape and calipers, including: curved carapace length (CCL), straight carapace length (SCL), and tail length (TL - from plastron to tip of tail). Sexual maturity was assumed for males exhibiting curved claws on front flippers, and a tail length $>40 \mathrm{~cm}$.

Plastron softness. We assessed a total of 32 turtles following a 'blind' evaluation (i.e. the reproductive status of the males was not known, in order to avoid bias). After capture and blood sampling, we positioned the turtle on its back and a trained observer delimited the area of plastron softness using a permanent marker. A second person was available to provide critical evaluation of the delimitation. Then, a digital image of the whole plastron was recorded from directly above the turtle. For measurement consistency, the same 2 persons delimited the area of all the turtles. In the lab, we developed a software application in the Python programming language (http://www.python.org) to enable calculation of the percentage of delineated softened area relative to the whole plastron based on the number of pixels. We used the TkInter widget toolkit to allow cross-platform availability (http://wiki.python. org/moin/TkInter). The PLastron Analysis Software Tool (PLASTron) is being developed as an opensource project that is freely available in binary and source versions (https://projects.dbbe.musc.edu/trac/ 
PLASTron/). Each plastron image was analyzed 3 times to evaluate measurement variability in the relative area calculation.

Ultrasonography. Ultrasound examinations were performed on all 40 adult males; however, due to improved technique after the first year, in terms of recognizing the structures of interest, we subsequently realized that ultrasound diagnostics were only reliable in the last 22 specimens (including 1 recaptured turtle). Examinations were performed using a SonoSite 180 Vet Plus (SonoSite) with a 4 to $7 \mathrm{Mhz}$ C11-type transducer. Examinations were performed just lateral to the plastron and cranial to the femurs on both the right and left sides. Prior to examination, the skin was gently cleaned of small barnacles and coupling gel was applied. Images were saved in the SonoSite 180, and later uploaded onto a laptop computer for improved viewing and long-term storage. We recorded measurements of internal structures, including epididymal duct diameters, using calipers built-in to the ultrasound system. Examination of each turtle required approximately $30 \mathrm{~min}$.

Laparoscopy. We performed laparoscopy on 32 of the 40 adult male loggerheads. Prior to laparoscopy, turtles were evaluated for physical condition and health status using standard blood chemistry (i.e. glucose, hematocrit, and total protein). Only turtles determined to be in excellent condition were subjected to laparoscopy. Turtles were prepared for laparoscopy as previously described by Wood et al. (1983) and Limpus \& Reed (1985). Turtles were held in dorsal recumbency, tilted head down, and covered with sterile surgical drapes. Local anesthetic was administered (2\% lidocaine hydrochloride, Vedco) within the inguinal region and we made a small incision $(0.5$ to $1 \mathrm{~cm})$ through which a $7 \mathrm{~mm} \times 17 \mathrm{~cm}$ trocar, a $7 \mathrm{~mm} \times 10.5 \mathrm{~cm}$ sleeve, and then the laparoscope $\left(7 \mathrm{~mm} \times 31 \mathrm{~cm}, 50^{\circ}\right.$ angle), were inserted into the peritoneal cavity. Filtered air (Gelman Acro 50, $0.2 \mu \mathrm{m}$ ) was pumped into the body cavity to allow for a better visualization of the internal organs. We first visualized internal structures with the naked eye, after which a BioVid digital color CCD camera (LW Scientific) was attached to the laparoscope allowing transmission of the image on both a 21-inch flat screen monitor and a laptop. Images and videos of the internal organs, including testes and epididymides, were recorded using AVerMedia DVD EZMaker (AVerMedia), and BioVid software. Adult male turtles were classified as reproductively active for the upcoming season if their testes showed distended seminiferous tubules and if their epididymal ducts were visibly engorged with semen. Reproductively inactive males had regressed testes and their epididymides were atrophied without clear evidence of sperm storage.
Occasionally (when time permitted), using a second incision (see below), a calibrated probe was inserted, allowing measurements of the epididymal duct diameters internally, which measurements were then compared to those recorded by ultrasonography as described above.

Testicular biopsy and histology. Following laparoscopic examination, we made a second incision 6 to $8 \mathrm{~cm}$ from the first one for the insertion of a second $5.5 \mathrm{~mm} \times$ $17 \mathrm{~cm}$ trocar, a $5.5 \mathrm{~mm} \times 10 \mathrm{~cm}$ sleeve, and biopsy forceps. A 2 to $6 \mathrm{~mm}^{3}$ sample was collected from 1 testis and placed in a vial containing $10 \%$ neutral buffered formalin. Both incisions were then sutured using 3-0 polydioxanone violet monofilament absorbable surgical suture (Vedco) after the air was manually expelled from the body cavity by 3 to 5 min of simultaneous direct pressure on the plastron and contra-lateral inguinal region. Following surgery, each turtle was placed in a tank filled with seawater so that normal activity and diving capabilities could be verified before release.

Biopsy samples were fixed and sectioned using standard paraffin histological techniques (Humason 1972). Sections were stained with hematoxylin/eosin-Y solutions. We analyzed and classified each sample into spermatogenetic stages based on Meylan et al. (2002) using a Nikon Eclipse 55i microscope equipped with a teaching head and a control unit, which displayed the images onto a PC monitor, allowing pictures to be taken. Seminiferous tubule maximum diameters were measured using the microscope and recorded to the nearest $10 \mu \mathrm{m}$ for a minimum of 3 tubules per turtle.

Testosterone and corticosterone analyses. Plasma testosterone and corticosterone levels were analyzed using a radioimmunoassay (RIA) similar to those described by Wibbels et al. (1987a) and Valverde (1996). All samples, in a volume of 3 to $250 \mu \mathrm{l}$ for testosterone analysis and 100 to $500 \mu \mathrm{l}$ for corticosterone analysis, were extracted (in triplicate for testosterone analysis due to the low volume of extraction) with $4 \mathrm{ml}$ diethyl ether and each sample was subsequently aliquoted for duplicate analysis. We purchased antibodies from Esoterix Laboratory Services and tritiated hormones from PerkinElmer Life and Analytical Sciences. Standard curves were prepared with known concentrations of radioinert corticosterone (ranging from 25 to $3200 \mathrm{pg}$ per tube) and testosterone (ranging 19.5 to $1250 \mathrm{pg}$ per tube) purchased from SigmaAldrich. We added respective antibodies and tritiated hormones $\left(10000 \mathrm{cpm} 100 \mathrm{\mu l}^{-1}\right)$ to the samples, standards, and controls accordingly. The unbound hormone in each tube was separated by dextran-coated charcoal and all tubes were centrifuged to separate bound and unbound fractions $(735 \times g$ for $15 \mathrm{~min}$ at $\left.4^{\circ} \mathrm{C}\right)$. Radioactivity from the tritiated hormone in the supernatant was counted for $60 \mathrm{~s}$ with a Wallac 1409 
liquid scintillation counter and concentrations of native testosterone/corticosterone in the samples were determined using the RIA Software (P. Licht, University of California, Berkeley). We corrected values by multiplying the volume extracted by the extraction efficiency (range: 85.2 to $97.1 \%$ ) and the fraction aliquoted from the reconstituted sample (40\%). A loggerhead control sample was extracted 4 times in each assay to evaluate intra-assay and inter-assay variability. The intra-assay and inter-assay coefficient of variations were 8.3 and $14.9 \%$, respectively, for testosterone analysis, and 7.1 and $13.6 \%$, respectively, for corticosterone analysis.

Evaluation of stress effects on hormone levels. To investigate the effect of time between blood sampling and laparoscopy (including testicular biopsy collection) on hormone levels, turtles were classified in the following categories: (1) turtles subjected or not subjected to laparoscopy; and (2) turtles for which a second blood sample (collected before release) was taken less than $10 \mathrm{~h}$ (mean $=5.4 \mathrm{~h}$, 'short-term release') or more than $10 \mathrm{~h}$ (mean $=20.2 \mathrm{~h}$, 'long-term release') after the initial sample. Turtles released more than $10 \mathrm{~h}$ after capture were all subjected to laparoscopy and were all kept on board overnight.

Statistical analysis. Statistical tests were performed using the software R version 2.6.2 (R Development Core Team). Assumptions for normality and equality of variances were tested using Shapiro-Wilks tests and Bartlett's tests, respectively. We used a Wilcoxon rank sum test to test for significant differences in CCL and TL between reproductively active and inactive males. Due to the strongly unbalanced sample sizes between active and inactive males, we used a permutation test and compared the result to a Wilcoxon rank sum test to test for significant differences in percent plastron softness between active and inactive males. The Pearson product-moment correlation coefficient was used to describe the relationship between epididymal duct diameters measured by laparoscopy and ultrasonography, testosterone levels and seminiferous tubule diameters, as well as between relative change in hormone levels over time. A linear mixed-effects model was used to test for significant differences in epididymal duct diameter measurements derived from laparoscopy versus ultrasound, with technique as the fixed effect, and individual turtles as the random effect. A likelihood ratio test was used to test for significant differences in epididymal duct diameters among individual turtles. A paired $t$-test was used to test for differences in hormone levels between samples collected after capture and just before release. An unpaired $t$ test was used to test for differences in testosterone levels between the first and second week of sampling in 2007 to detect for monthly variations. One-way
ANOVAs were used to test for relative changes in testosterone and corticosterone levels between turtles evaluated by laparoscopy and turtles not evaluated under laparoscopy over a short-term or a long-term release. We used a Tukey's HSD post hoc test to evaluate multiple comparisons. All numbers are reported as mean $\pm 1 \mathrm{SE}$, and $\alpha=0.05$ for all tests.

\section{RESULTS}

\section{Morphometrics}

CCL (notch to notch) averaged $98.2 \pm 1.1 \mathrm{~cm}$ (range: 87.6 to $109.3 \mathrm{~cm}$ ) and TL averaged $49.0 \pm 0.8 \mathrm{~cm}$ (range: 41.8 to $62 \mathrm{~cm}$ ). SCL measurements were not used since our calipers were not long enough to obtain the measurements in some cases. There was no significant difference in CCL or TL between the reproductively inactive and active males (Wilcoxon rank sum test, $W=46, \mathrm{p}=0.31$ and $\mathrm{p}=0.60$, for $\mathrm{CCL}$ and $\mathrm{TL}$, respectively).

\section{Plastron softness}

The mean coefficient of variation between the 3 measurements of relative percent softened area per turtle was $1.8 \%$, indicating good reproducibility in this calculation. The percentage of plastron softness ranged from 8.2 to $57.8 \%$ across all 32 turtles. Because no study has ever tried to relate plastron softness to reproductive activity in male sea turtles, we classified turtles into one or the other category (reproductively active or inactive) based on laparoscopy. Mean percentage of relative plastron-softened area was $25.2 \%$ (range: 8.2 to $37.8 \%$ ), and $42.5 \%$ (range: 25.4 to $57.8 \%$ ) for reproductively inactive males and active males, respectively (Fig. 1). There was a significant difference in average percent plastron-softened area between both groups (permutation test, $T=44,10000$ iterations, $\mathrm{p}<0.005$, confirmed with a Wilcoxon Rank Sum test, $W=15, \mathrm{p}<0.05)$. Fig. 2 shows the plastron of a reproductively active male.

\section{Ultrasonography}

During ultrasound evaluation, kidneys were also observed, providing a point of reference when searching for the gonads. Testes were usually found between the intestine loops and the kidneys, and presented a homogeneous echopattern that was slightly hyperechoic to the kidney parenchyma (Fig. 3a). Testicular foldings could sometimes be observed. Epididymides 


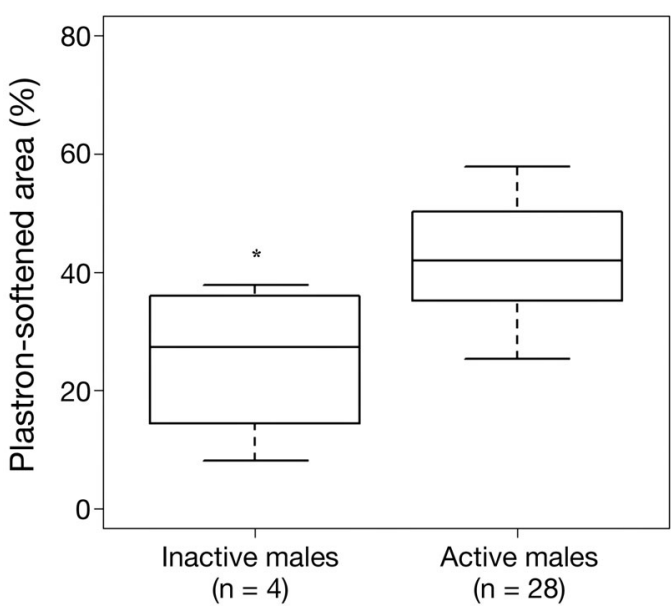

Fig. 1. Caretta caretta. Percent plastron-softened area in reproductively inactive and active males. Sample size is indicated below each box. Whiskers show range, box represents interquartile range with median. Significant difference between each group indicated by asterisk

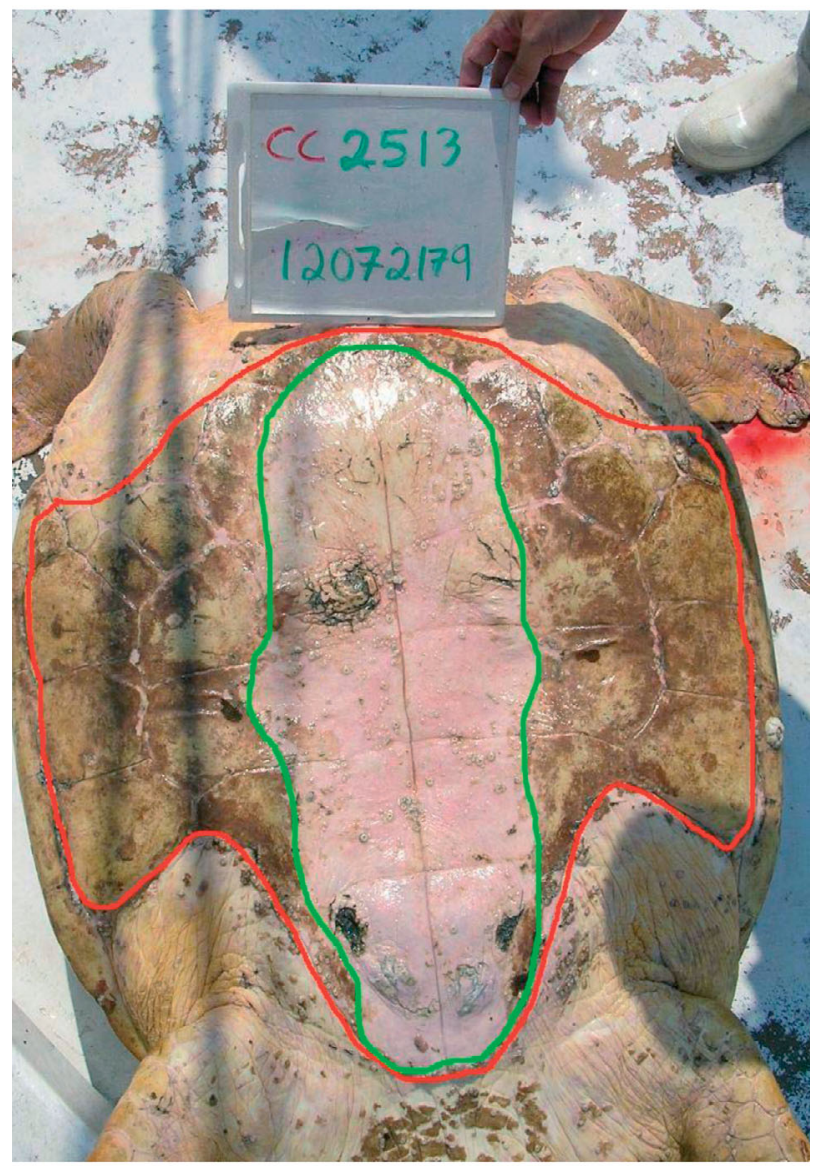

Fig. 2. Caretta caretta. Plastron of a reproductively active male (plastron-softened area $=45.9 \%$ ). Red line shows plastron outline, green line shows softened area outline
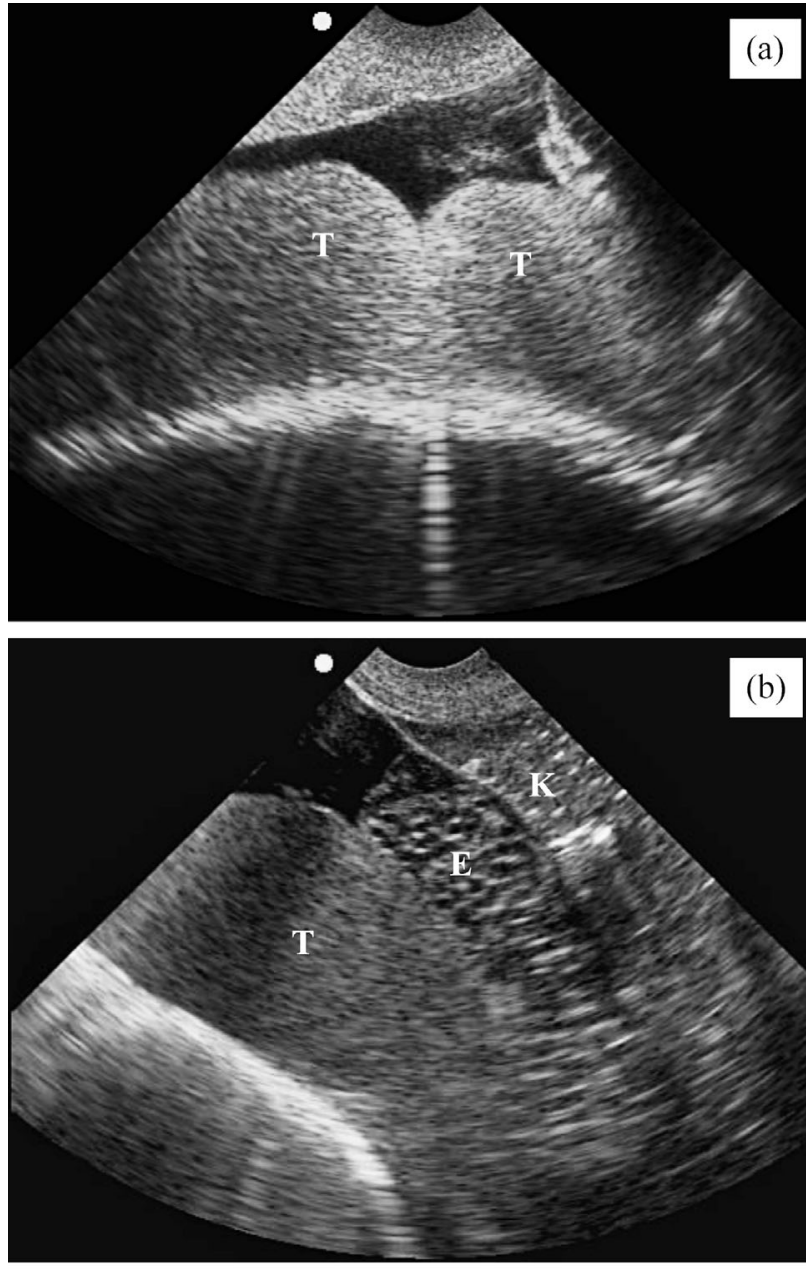

Fig. 3. Caretta caretta. Ultrasound images of (a) testis and (b) epididymis in a reproductively active adult male $(\mathrm{T}=$ testes, $\mathrm{E}=$ epididymis, $\mathrm{K}=$ kidney)

were usually found caudal to the testes, between the testes and the kidneys. They appeared as a mass of many small tubular structures, containing anechoic fluid, suggesting these males were reproductively active for the current breeding season (Fig. 3b). The diameter of these tubules was evaluated using a minimum of 10 measurements. The average epididymal duct diameter was $2.71 \pm 0.10 \mathrm{~mm}$ (range: 2.04 to $3.50 \mathrm{~mm}, \mathrm{n}=22$ ). The epididymides were seen in all 22 turtles whose examinations were deemed reliable; therefore we classified them as being reproductively active. However, 4 non-reproductive males, as described below, were not examined by ultrasound.

\section{Laparoscopy}

Testes were seen in all 32 turtles examined and epididymides were observed in 31 cases. Out of the 32 
turtles examined by laparoscopy, 4 were classified as being reproductively inactive, in which testes appeared regressed and flaccid, seminiferous tubules were not clearly visible, and epididymides were atrophic with no distinct tubules (Fig. 4). The other 28 turtles were all described as reproductively active on the basis of the appearance of both the testes and epididymides. Testes appeared as a pinkish mass, often folded (as sometimes seen during the ultrasound evaluation), and turgid in most cases (Fig. 5a). Seminiferous tubules could be observed in many instances. In reproductively active individuals epididymides appeared as white convoluted tubules, full of semen (Fig. 5b).

In 10 turtles, we used the second entry to insert a calibrated probe to measure the epididymal duct diameter internally (a minimum of 10 measurements per turtle were recorded). The average duct diameter was $2.85 \pm 0.13 \mathrm{~mm}$ (range: 2.10 to $3.61 \mathrm{~mm}$ ). Duct diameters on the same 10 turtles using ultrasonography aver-
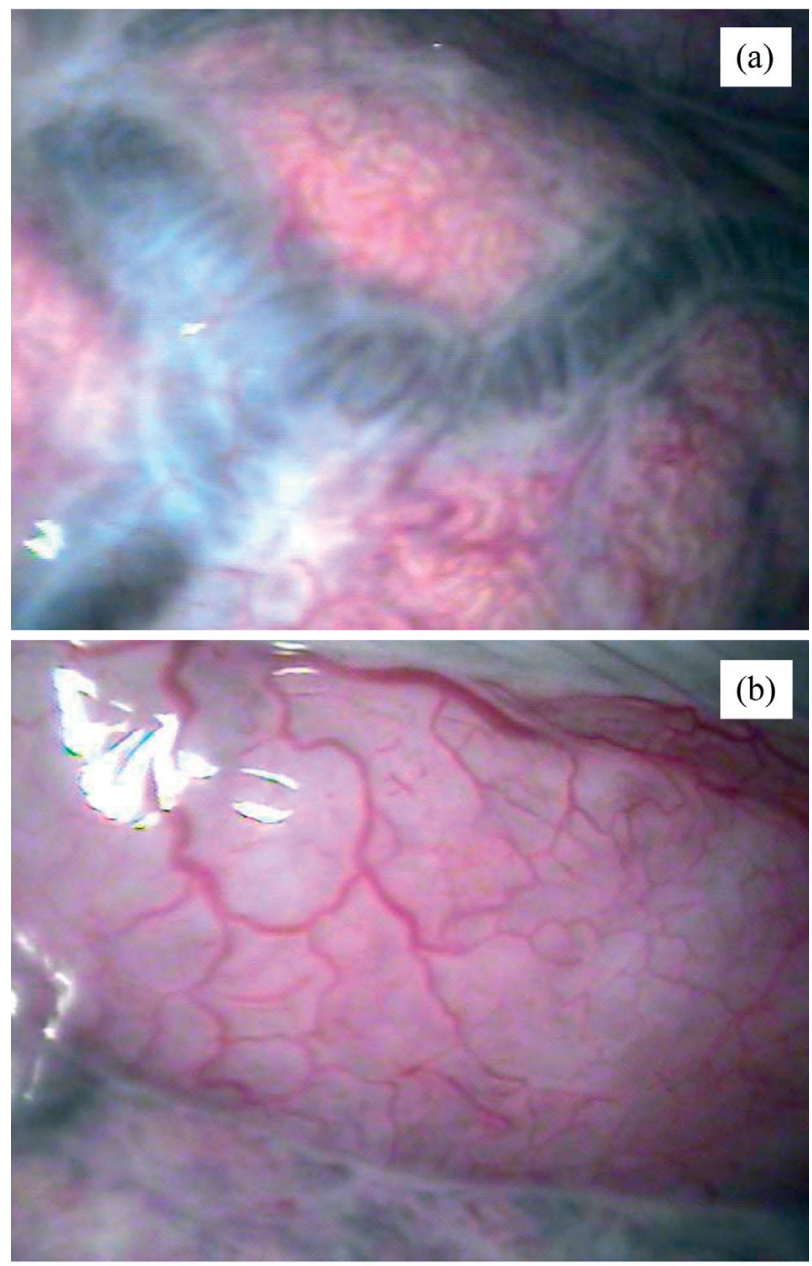

Fig. 4. Caretta caretta. (a) Testis and (b) epididymis in a reproductively inactive male during laparoscopy
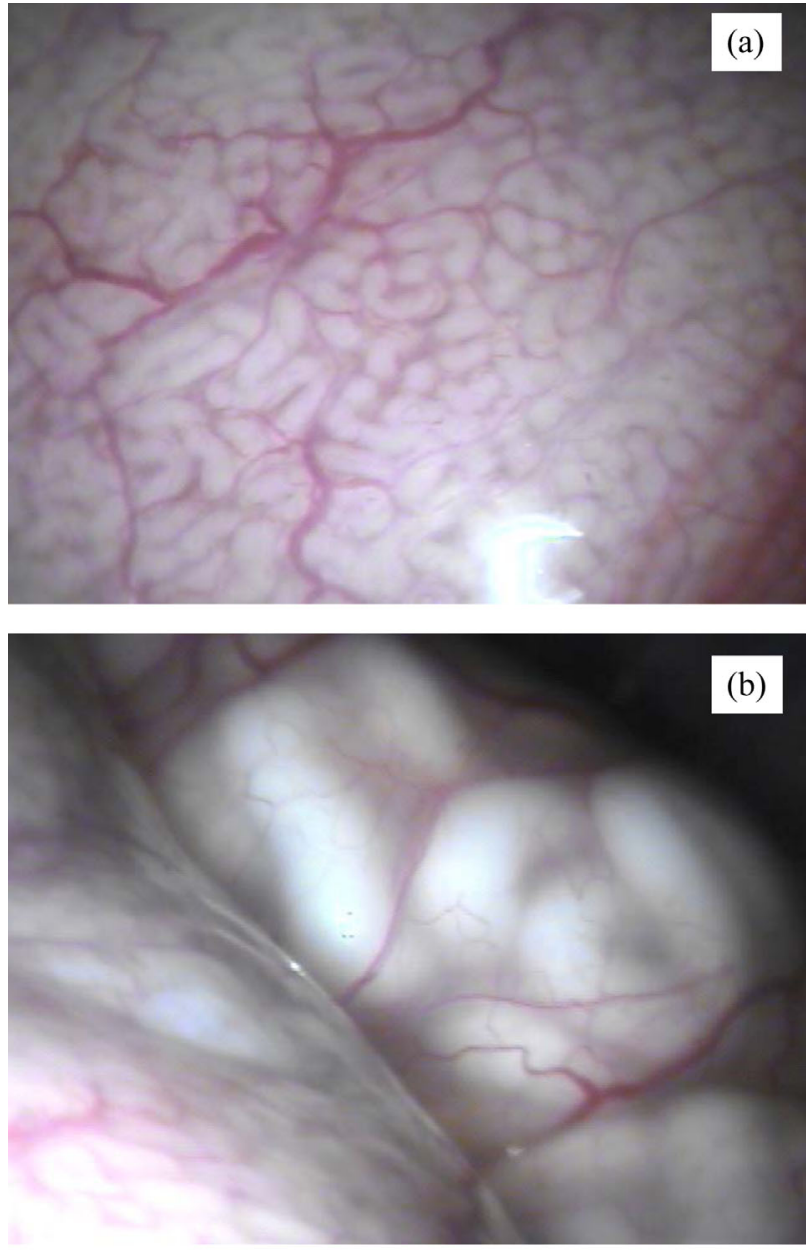

Fig. 5. Caretta caretta. (a) Testis exhibiting distended seminiferous tubules and (b) epididymis engorged with semen in a reproductively active male during laparoscopy

aged $2.76 \pm 0.12 \mathrm{~mm}$ (range: 2.12 to $3.34 \mathrm{~mm}$ ). There was a significant positive relationship between epididymal duct diameter measured by ultrasonography and epididymal duct diameter measured during laparoscopy (Pearson's $r=0.91, \mathrm{n}=10, \mathrm{p}<0.001$ ). A linear mixed-effects model looking at the effect of technique (ultrasound and laparoscopy) on the diameter of the epididymides revealed no statistical difference between techniques $(p=0.14)$. However, epididymal duct diameters varied significantly across individual turtles (likelihood ratio test, $\mathrm{L}$ ratio $=16.47$, $\mathrm{p}<0.0001$ ) (Fig. 6)

\section{Histology}

Testicular biopsies proved to be a powerful tool in determining the reproductive status of adult loggerhead males. With the exception of 4 individuals from 


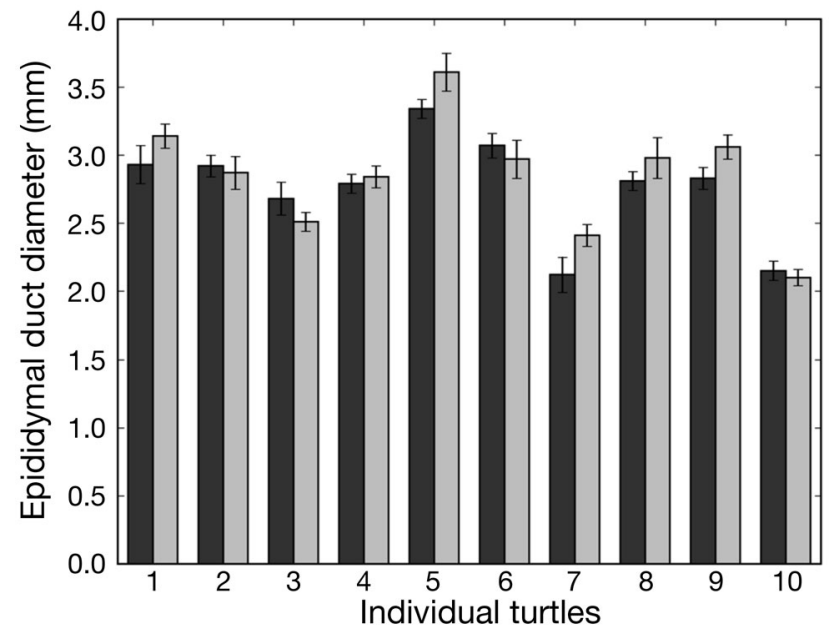

Fig. 6. Caretta caretta. Variation in epididymal duct diameter (in $\mathrm{mm}$ ) measured by ultrasonography (dark gray bars) and laparoscopy (light gray bars) in adult males. Diameters did not vary significantly based on the technique used, but were significantly different across individual turtles

the first year for which we did not have enough material to make a conclusion (including 1 turtle classified as inactive during laparoscopy), we found that 3 males were inactive, as observed during laparoscopy (Stage 1 of spermatogenesis, small tubule diameter, see Fig. 7a). All other males were at Stage 5 to 7 or later (defined as 'post-spermatogenic', see Fig. 7b), clearly demonstrating that they were reproductively active that season. The average seminiferous tubule diameter was $135.7 \pm 8.2 \mu \mathrm{m}(\mathrm{n}=3)$, and $359.8 \pm$ $8.8 \mu \mathrm{m}(\mathrm{n}=25)$ for reproductively inactive and active males, respectively.

\section{Hormone levels}

Testosterone levels from plasma samples collected just after capture, in both 2006 and 2007, ranged from 1.23 to $188 \mathrm{ng} \mathrm{ml}^{-1}$. Three samples in 2006 and 1 in 2007 were below $5 \mathrm{ng} \mathrm{ml}^{-1}$ and corresponded to the 4 turtles classified as reproductively inactive using laparoscopy and by histological analysis of the testicular biopsy samples. The average testosterone level for reproductively inactive males was $2.82 \pm 0.66 \mathrm{ng} \mathrm{ml}^{-1}$. The other 36 samples all came from reproductively active males and ranged from 16.66 to $188 \mathrm{ng} \mathrm{ml}^{-1}$ $\left(\right.$ mean $\left.=113 \pm 6.45 \mathrm{ng} \mathrm{ml}^{-1}\right)$. Testosterone levels measured across each sampling week and separated by reproductive category (inactive and active) are shown in Fig. 8 (levels for inactive males were pooled across both years due to the low sample size and small variability). When levels below $5 \mathrm{ng} \mathrm{ml}^{-1}$ were excluded from the analysis, there was a significant drop in
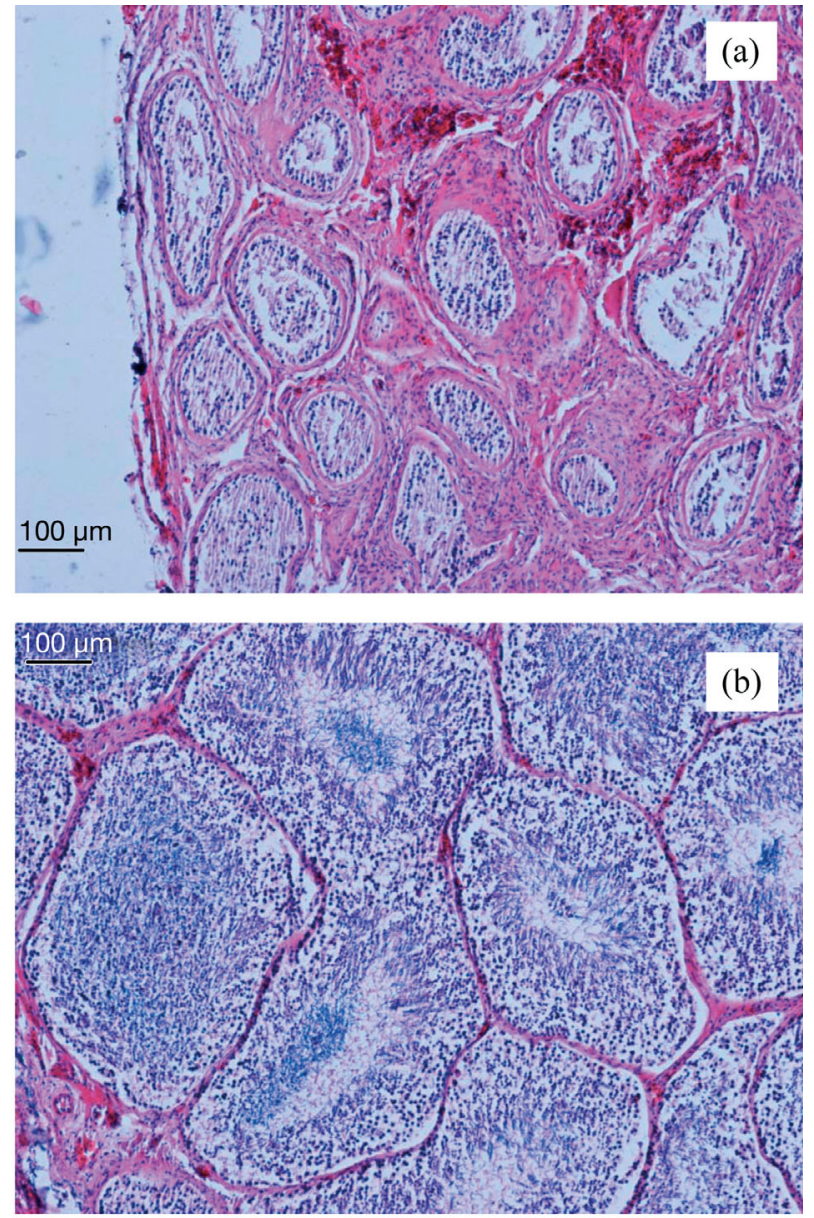

Fig. 7. Caretta caretta. Histological pictures from testicular biopsy of (a) an inactive male (seminiferous tubules are small, classified as Stage 1) and (b) an active male (seminiferous tubules are large, spermatozoa are migrating towards the center of the tubules, classified as Stage 6).

testosterone levels between the first week (mean $=137$ $\pm 8.1 \mathrm{ng} \mathrm{ml}^{-1}$ ) and the second week (mean $=88.7 \pm$ $9.2 \mathrm{ng} \mathrm{ml}^{-1}$ ) of capture in 2007 ( $t$-test, $t=3.71$, $\mathrm{df}=26$, $\mathrm{p}<0.001$ ). Because of probable annual fluctuations in the timing of the mating season and testosterone cycle in adult males, we did not attempt to compare levels in 2006 to those in 2007. Testosterone levels were not correlated with epididymal tubule diameter nor with percent relative plastron-softened area; however, there was a significant positive relationship between testosterone levels and seminiferous tubule diameters (Pearson's $r=0.65, \mathrm{p}<0.0005$ ).

On average, testosterone levels dropped 24.5\% between the time the initial samples (after capture, 'Sample 1') and the second sample (before release, 'Sample 2') were collected. This decrease in testosterone concentrations was statistically significant across all turtles (paired $t$-test, $t=5.96$, df $=26, \mathrm{p}<$ 0.0001). Conversely, corticosterone levels ranged from 


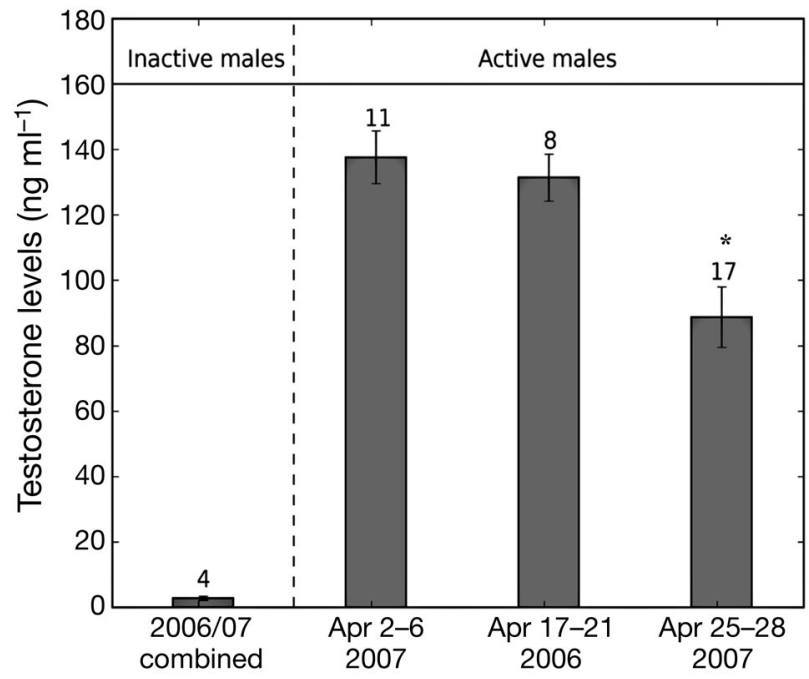

Fig. 8. Caretta caretta. Testosterone levels of adult males for each reproductive category (active and inactive) and across each sampling week. Values are mean $\pm \mathrm{SE}$, sample sizes indicated on top of each bar. Significant difference between testosterone concentrations during the first and second week of capture in 2007 indicated by asterisk

0.12 to $6.14 \mathrm{ng} \mathrm{ml}^{-1}$ on samples collected just after capture $\left(\right.$ mean $=1.25 \pm 0.21 \mathrm{ng} \mathrm{m}^{-1}$ ) and from 2.12 to $23.73 \mathrm{ng} \mathrm{ml}^{-1}$ on samples collected before release (mean $=8.23 \pm 0.96 \mathrm{ng} \mathrm{ml}^{-1}$ ). It is interesting to note that the 1 inactive male captured in 2007 had the highest corticosterone concentration among samples collected before release $\left(23.73 \mathrm{ng} \mathrm{ml}^{-1}\right)$. There was a significant increase in corticosterone levels between the 2 paired samples collected for each turtle (paired $t$-test, $t=-7.68, \mathrm{df}=26, \mathrm{p}<0.0001$ ); however, there was no significant relationship between the relative change in corticosterone levels between Sample 1 and Sample 2 and the number of hours the turtles remained in captivity (Pearson's $r=-0.19, \mathrm{p}=0.33$ ). In contrast, there was a significant negative correlation between the relative change in testosterone levels between Sample 1 and Sample 2 and time in captivity, i.e. the longer we waited to collect the second blood sample, the lower the testosterone level was compared to that of the initial sample (Pearson's $r=-0.82, p<0.0001$ ) (Fig. 9).

Although the average relative corticosterone change for the short-term release group (time between Sample 1 and Sample $2<10 \mathrm{~h}$ ) was twice as high in turtles that were evaluated by laparoscopy $(n=10)$ compared to those that were not $(\mathrm{n}=6)$, we found no statistically significant differences in relative corticosterone change between groups. Also, there was no statistical difference between short-term release (laparoscoped and non laparoscoped) and long-term release groups (time between Sample 1 and Sample $2>10 \mathrm{~h}, \mathrm{n}=11$ ), although corticosterone levels decreased considerably

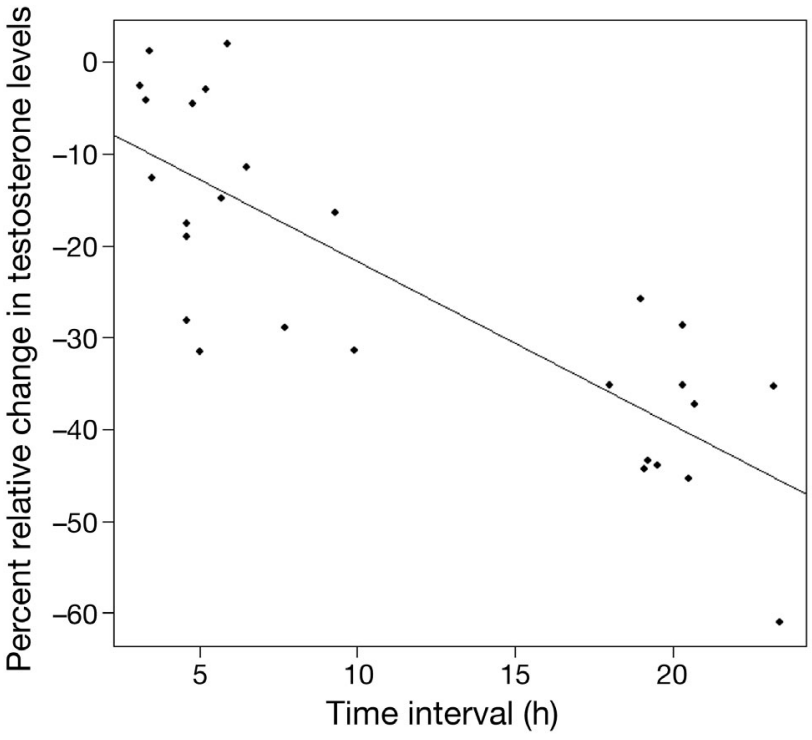

Fig. 9. Caretta caretta. Correlation between the percent relative change in testosterone concentration in adult males between initial blood sample (collected after capture) and second blood sample (collected before release) over time
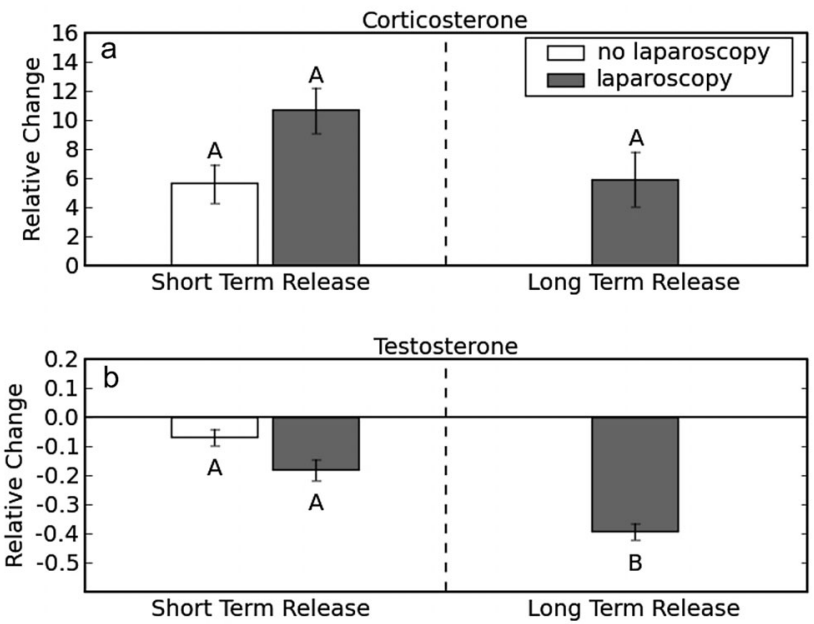

Fig. 10. Caretta caretta. Testosterone and corticosterone relative change between initial sample collected after capture (Sample 1), and second sample collected before release (Sample 2). 'Short-term release' indicates turtles were released less than $10 \mathrm{~h}$ after capture, 'long-term release' indicates turtles were kept on board for more than $10 \mathrm{~h}$, overnight. Values are means \pm 1 SE. Different letters on top of bars show significant difference among groups

in the long-term release group (ANOVA $F_{2,24}=2.46$, $\mathrm{p}=0.11$ ) (Fig. 10a). Following the same study design, there was no statistical difference in relative testosterone change between laparoscoped and non-laparoscoped turtles in the short-term release group (Tukey's HSD, $p=0.12$ ), although testosterone levels dropped 
3 times as much in turtles subjected to laparoscopy, compared to those that were not. However, there was a significant drop in relative testosterone change between the long-term and the short-term release groups (Tukey's HSD, p < 0.0005, Fig. 10b).

\section{DISCUSSION}

Laparoscopy, testicular biopsies, and testosterone analyses have all been used in the past as a way to investigate the reproductive activity of adult male sea turtles (e.g. Wibbels et al. 1990, Plotkin et al. 1996, Jessop et al. 2004). Laparoscopy, in particular, has the advantage of directly visualizing the gonads, allowing the investigator to make a straightforward diagnosis of reproductive and maturity status. In addition, testicular biopsies reveal the stage of spermatogenesis of the turtle, which is a powerful tool; however, this technique not only requires invasive surgery, but also necessitates a significant amount of laboratory work, rendering a complete understanding of the turtle's reproductive status impossible while in the field. Moreover, laparoscopic surgery followed by testicular biopsy may cause a relatively high (though variable) level of stress in the turtles (based on serum corticosterone and testosterone concentrations), and a substitute for this technique would be desirable.

The measure of plasma testosterone levels in male sea turtles is also of interest, since reproductively active males should exhibit an increase in testosterone concentrations during the premating season, which correlates with their peak of density in the Canaveral area, during the months of March and April (Henwood 1987). At this time of the year, testicular development is also maximal (peak of spermatogenesis), as shown by the significant correlation we found between testosterone levels and seminiferous tubule diameters, and the epididymides should be packed with sperm. Wibbels et al. (1987b) measured plasma testosterone levels for 80 adult male loggerheads captured in the Cape Canaveral shipping channel between January and August from 1981 to 1983. Hormone levels from that early work discussed below have been corrected from their original values based on a calculation error discovered by Lee (2003) and discussed by BraunMcNeill et al. (2007). Testosterone levels in Wibbels et al. (1987b) exhibited 2 trends: $13.8 \%$ of the captured turtles had consistently low concentrations $\left(<5 \mathrm{ng} \mathrm{ml}^{-1}\right)$ for several months of the year, whereas $86.2 \%$ had much higher concentrations, reaching $244.8 \mathrm{ng} \mathrm{ml}^{-1}$ in mid-February. When both groups of males (those with low and high testosterone concentrations) were separated for analysis, males with higher concentrations showed a peak of testosterone in February and March, corresponding to their migration into the channel. Testosterone concentrations then started to decrease significantly in May. Unfortunately, Wibbels et al. (1987b) were not able to confirm with laparoscopy if animals with low concentrations were indeed reproductively inactive. Our findings correlate with this study, showing $10 \%$ of reproductively inactive males in 2006 and 2007 combined with testosterone concentrations below $5 \mathrm{ng} \mathrm{ml}^{-1}$ and reproductively active males with much higher concentrations, reaching 188 $\mathrm{ng} \mathrm{m} \mathrm{m}^{-1}$. Based on our results and on the study by Wibbels et al. (1987b), it appears that about 10 to $15 \%$ of adult males at Cape Canaveral do not participate in breeding activity in a given year. Similar results have been found in green sea turtles in Queensland, Australia, where $21 \%$ of adult males were inactive (Jessop et al. 2004), suggesting that adult male sea turtles, like females, may have multiannual reproductive cycles, possibly driven by food availability and individual health status. However, in Wibbels et al. (1990), all male loggerheads captured at Heron Island, Australia, exhibited high testosterone levels during winter and spring. In addition, the 1 male turtle we captured both in 2006 and 2007 was reproductively active both years, suggesting males might reproduce annually much of the time and only 'skip' a year a small percentage of the time. Since reproductively inactive males may not migrate to reproductive areas such as Heron Island or Cape Canaveral, more careful studies on this question of male cyclicity are required.

We suspected that the presence of a soft plastron could be a sign of sexual maturity in adult male sea turtles, which would allow scientists to make predictions of sexual maturity fairly easily during field studies. It has been noted by previous investigators that the plastron of adult male sea turtles was often relatively soft and lacking the keratinized layer when captured during the breeding season (Wibbels et al. 1991, Plotkin et al. 1996, Shaver et al. 2005). Wibbels et al. (1991) originally described and reported that this occurrence of 'soft plastra' in adult male loggerheads was common in the Cape Canaveral shipping channel, but they did not undertake a complete survey of this incidence. They hypothesized that it could be a secondary sexual characteristic that could facilitate male turtles in successfully mounting females during the breeding season by reducing slippage and/or increasing tactile sensation. They also noted that all immature turtles and adult females had well-keratinized plastra. However, evaluating the plastron softness to assess the reproductive activity level of adult male turtles has to be done with caution, since immature males have also been found with elongated tails and signs of a prolonged period of plastron dekeratinization during sexual maturation (Hickerson 2000). 
Our study shows that the average percent of softened area was significantly lower for the inactive males compared to the active males; however, this finding was probably influenced by 1 turtle, which had a much lower percent softened area than the other 3 inactive males. The fact that there was no significant difference in CCL between reproductively inactive and active males strongly suggests that the difference in percent softened area observed in our study was not due to maturity status (juvenile/pubescent vs. adult), but rather to a physiological difference once adulthood is reached. Nevertheless, the percent softened area between active and inactive males overlapped to some extent, indicating that interpretation errors could be made if assessing the reproductive activity of adult male sea turtles for a specific breeding season using this technique alone. Given our low sample size of inactive males and the promising results using this technique, further investigation will be needed, particularly to determine if this secondary sexual characteristic is acquired at adulthood and does not change thereafter, or if there is an annual cycle of dekeratinization during the breeding season and keratinization outside of the breeding season.

Ultrasonography has been used in the past to evaluate the reproductive status of adult female turtles, providing a powerful tool in the field to investigate if females have follicles and/or eggs (Kuchling 1989, Rostal et al. 1990, 1997, 1998). In addition, ultrasound analysis has the advantage of allowing investigators to take a variety of measurements noninvasively, in a relatively short time. Recently, Valente et al. (2007) provided ultrasound images of various internal structures in juvenile loggerhead sea turtles; however, they could not identify underdeveloped gonads using this technique. No previous studies have looked at adult male turtle gonads using ultrasonography, however, Brook et al. (2000) investigated the ultrasound imaging of testes and epididymides in the bottlenose dolphin Tursiops truncatus aduncas, with their results being very similar to our findings in the general appearance of both reproductive structures in active males. Moreover, the significant correlation we found between epididymal duct diameters measured during laparoscopy and by ultrasound on the same set of turtles suggests that ultrasonography can be used successfully as a substitute for laparoscopic surgery to learn whether adult male loggerheads are reproductively active during a given season. Unfortunately, we did not perform ultrasonography on reproductively inactive males (the 4 inactive males captured in this study were subjected to ultrasound analysis before A. Pease joined our field research team); therefore, more work with non-reproductive males, such as on the foraging grounds, is needed.

\section{CONCLUSION}

Laparoscopic evaluation (along with testicular biopsies) remains the most effective tool for the determination of the reproductive status of male sea turtles, but it is also a more invasive and stressful technique that can lead, in rare cases, to the death of the turtle (Wibbels et al. 1987a). However, in this 2 yr study, turtles showed no sign of post-surgical trauma based on up to $16 \mathrm{~h}$ of initial observation and satellite tracking shows these animals are capable of migrating hundreds of $\mathrm{km}$ post surgery (SCDNR unpubl. data). Also, the 1 turtle we recaptured and subjected to laparoscopy a second time had completely healed with no superficial or internal scar tissue observed. Nevertheless, the implementation of this technique can be challenging in the field and it can only be practiced by trained scientists and veterinarians. Other techniques investigated in this study proved that they could be used as substitutes for laparoscopy. In particular, ultrasonography is very promising, since we were able to visualize both the testes and the epididymides. However, further evaluation on reproductively inactive males will be needed to confirm the full potential for use of this technique in adult males. The analysis of plastron softness also represents a potential way to investigate the reproductive activity of adult males, as we found significant differences between both groups of males. More work will be needed with a larger sample size of inactive males. Finally, testosterone analysis separated the active males from the inactive males in 2 distinct groups, however, it can not be used in the field at this time, as it requires several days of laboratory work. Also, testosterone analysis would have to be done on samples collected during the pre-mating season, as testosterone levels decrease drastically during mating and thereafter, as suggested in this study, with the much lower concentrations measured in males captured the last week of April.

Acknowledgements. The authors thank M. Arendt and J. Byrd for their invaluable help in the field and for their critical review of this manuscript. We also thank the RV 'Georgia Bulldog' crew (L. Parker, M. Higgins, R. Puterbaugh, J. Dickey), K. Mazzarella from the College of Charleston, and all the volunteers who assisted in the field. A special thanks to A. Strand for statistical advice and to D. Rotstein and the SCDNR histology facility for helping with the histological analysis. This research was funded by the National Marine Fisheries Service (grant \#NA03NMF4720281), and all methods were approved by NMFS (permit \#1540). The institutional Animal Care and Use Committee of the College of Charleston approved all capture and handling protocols (IACUC-2006007). This is contribution 330 of the Grice Marine Laboratory, College of Charleston, Charleston, South Carolina, USA. 


\section{LITERATURE CITED}

Braun-McNeill J, Epperly SP, Owens DW, Avens L, Williams E, Harms CA (2007) Seasonal reliability of testosterone radioimmunoassay (RIA) for predicting sex ratios of juvenile loggerhead (Caretta caretta) turtles. Herpetologica 63:275-284

Brook FM, Kinoshita R, Brown B, Metreweli C (2000) Ultrasonographic imaging of the testis and epididymis of the bottlenose dolphin, Tursiops truncatus aduncus. J Reprod Fertil 119:233-240

FitzSimmons NN, Limpus CJ, Norman JA, Goldizen AR, Miller JD, Moritz C (1997) Philopatry of male marine turtles inferred from mitochondrial DNA markers. Proc Natl Acad Sci USA 94:8912-8917

Frick MG, Slay CK, Quinn CA, Windham-Reid A, Duley PA, Ryder CM, Morse LJ (2000) Aerial observations of courtship behavior in loggerhead sea turtles (Caretta caretta) from southeastern Georgia and northeastern Florida. J Herpetol 34:153-158

Henwood TA (1987) Movements and seasonal changes in loggerhead turtle Caretta caretta aggregations in the vicinity of Cape Canaveral, Florida (1978-84). Biol Conserv 40: 191-202

Hickerson E (2000) Assessing and tracking resident, immature loggerheads (Caretta caretta) in and around the Flower Garden Banks, northwest Gulf of Mexico. MSc thesis, Texas A\&M University, College Station, TX

Humason GL (1972) Animal tissue techniques. WH Freeman, San Francisco, CA

> Jessop TS, Limpus CJ, Whittier JM (2004) Comparison of plasma androgen profiles in green and hawksbill sea turtles inhabiting Queensland waters. Aust J Zool 52: 293-301

Kuchling G (1989) Assessment of ovarian follicles and oviductal eggs by ultra-sound scanning in live freshwater turtles, Chelodina oblonga. Herpetologica 45:89-94

Lee M (2003) Reproductive biology and seasonal testosterone patterns of the diamondback terrapin, Malaclemys terrapin, in the estuaries of Charleston, South Carolina. MSc thesis, University of Charleston, Charleston, SC

Limpus CJ (1993) The green turtle, Chelonia mydas, in Queensland: breeding males in the Southern Great Barrier Reef. Wildl Res 20:513-523

Limpus CJ, Reed PC (1985) The green turtle, Chelonia mydas, in Queensland: a preliminary description of the population structure in a coral reef feeding ground. In: Grigg G, Shine R, Ehmann H (eds) Biology of Australasian frogs and reptiles. R Zool Soc New South Wales, Sydney, p 47-52

Meylan PA, Schuler R, Moler P (2002) Spermatogenic cycle of the Florida softshell turtle, Apalone ferox. Copeia 2002: 779-786

Owens DW, Ruiz GJ (1980) New methods for obtaining blood

Editorial responsibility: Matthew Godfrey,

Beaufort, North Carolina, USA and cerebrospinal fluid from marine turtles. Herpetologica 36:17-20

Plotkin PT, Owens DW, Byles RA, Patterson R (1996) Departure of male olive ridley turtles (Lepidochelys olivacea) from a nearshore breeding ground. Herpetologica 52: $1-7$

Rostal DC, Robeck TR, Owens DW, Kraemer DC (1990) Ultrasound imaging of ovaries and eggs in Kemp's ridley sea turtles (Lepidochelys kempi). J Zoo Wildl Med 21:27-35

Rostal DC, Grumbles JS, Byles RA, Márquez-M R, Owens DW (1997) Nesting physiology of Kemp's Ridley sea turtles, Lepidochelys kempi, at Rancho Nuevo, Tamaulipas, Mexico, with observations on population estimates. Chelonian Conserv Biol 2:538-547

Rostal DC, Owens DW, Grumbles JS, MacKenzie DS, Amoss MS Jr (1998) Seasonal reproductive cycle of the Kemp's Ridley sea turtle (Lepidochelys kempi). Gen Comp Endocrinol 109:232-243

Shaver DJ, Schroeder BA, Byles RA, Burchfield PM, Peña J, Márquez R, Martinez HJ (2005) Movements and home ranges of adult male Kemp's Ridley sea turtles (Lepidochelys kempii) in the Gulf of Mexico investigated by satellite telemetry. Chelonian Conserv Biol 4:817-827

Valente AL, Parga ML, Espada Y, Lavin S, Alegre F, Marco I, Cuenca R (2007) Ultrasonographic imaging of loggerhead sea turtles (Caretta caretta). Vet Rec 161:226-232

Valverde RA (1996) Corticosteroid dynamics in a free-ranging population of olive Ridley sea turtles (Lepidochelys olivaea Eschscholtz, 1829) at Playa Nancite, Costa Rica, as a function of their reproductive behavior. $\mathrm{PhD}$ thesis, Texas A\&M University, College Station, TX

Wibbels T, Owens DW, Morris YA, Amoss MS (1987a) Sexing techniques and sex ratios for immature loggerhead sea turtles captured along the Atlantic coast of the United States. In: Witzell W (ed) Ecology of East Florida sea turtles. U.S. Dept Commer, NOAA Tech Rep NMFS 53, p 65-74

Wibbels T, Owens DW, Amoss M (1987b) Seasonal changes in serum testosterone of loggerhead sea turtles captured along the Atlantic coast of the United States. In: Witzell W (ed) Ecology of East Florida Sea Turtles. U.S. Dept Commer, NOAA Tech Rep NMFS 53, p 59-64

Wibbels T, Owens DW, Limpus CJ, Reed PC, Amoss MS Jr (1990) Seasonal changes in serum gonadal steroids associated with migration, mating, and nesting in the loggerhead sea turtle (Caretta caretta). Gen Comp Endocrinol 79:154-164

Wibbels T, Owens DW, Rostal D (1991) Soft plastra of adult male sea turtles: an apparent secondary sexual characteristic. Herpetol Rev 22:47-49

Wood JR, Wood FE, Critchley KH, Wildt DE, Bush M (1983) Laparoscopy of the green sea turtle, Chelonia mydas. Brit J Herpetol 6:323-327

Submitted: May 1, 2008; Accepted: August 27, 2008

Proofs received from author(s): October 11, 2008 